\title{
Lounaismurteiden translatiivisia verbityyppejä
}

Suomen lounaismurteiden eräät verbityypit poikkeavat muiden murrealueiden vastaavista omalla erikoisella tavallaan. Lounaismurteiden keskeisimmillä puhumaalueilla ei perinteisesti esiinny ollenkaan ne-johtimisia verbejä (ks. Räisänen 1985), jotka ovat muilla murrealueilla tavallisia. Mainitut verbit ovat lounaismurteissa jäännöksettömästi ikään kuin korvautuneet vastaavilla $n t u / n t y$-johtimisilla verbeillä (esim. yleisk. pitenee LM piðènty). Tilanne on samanlainen kuin liivin kielessä (Laakso 1990: 115-116), jossa siinäkin näyttää tapahtuneen vastaavanlainen korvautuminen; lounaismurteiden kantaa Laakso (mt.) ei väitöskirjassaan tuo esille.

Tässä kirjoituksessa tarkastelen ja luokittelen lounaismurteiden ntu/ntyjohtimisia verbejä. Ne ovat useimmiten translatiivisia eli ilmaisevat lauseen subjektin muuttumista kantasanan tarkoittamaksi. Edellä mainittu alue käsittää Räisäsen (1985: 10) mukaan ainakin Sauvon, Maskun, Merimaskun, Mietoisten ja Honkilahden, mutta siihen voidaan lisätä vielä moni muukin VarsinaisSuomen pitäjä, kuten Vahto, Nousiainen, Mynämäki, Taivassalo ja Kalanti. Esittelen myös toisen murrealueella tunnetun translatiivisen verbityypin, nimittäin stu/sty-johtimisen variantin, joka eroaa $n t u / n t y$-johtimisesta semanttisesti niin, että verbi ilmaiseekin lauseen subjektin saavan kantasanasta johdetun adjektiivin ominaisuutta. Tämä johdosverbityyppi on frekvenssiltään melko pieni.

Tämän tutkimuksen aineiston olen koonnut enimmäkseen 1980-luvun loppupuolella Maskun murrealueelta, jolla tarkoitan Maskun ja sen lähipitäjien muo- dostamaa aluetta ja jonka murteen hallitsen vuosikymmeniä siellä asuneena ja työskennelleenä. Kyseinen alue on lounaismurteiden ydinaluetta. Molempien verbityyppien levikki ulottuu lounaismurteiden pohjoisessa haarassa ainakin $\mathrm{Ka}$ lantiin saakka. ntu/nty-valtaisuus on jopa voittanut jonkin verran alaa tämän alueen ulkopuolellakin (ks. Räisänen 1985: 11). stu/sty-johtimisista verbeistä rajoitun vain lounaismurteille ominaisiin 'jollakin tahriutumista' tarkoittaviin, tahrivan aineen ilmaiseviin translatiiviverbeihin (esim. Kahlates liajustu aika tavàl, muk kyl uiðes sit pessenty taas).

Sekä ntu/nty- että stu/sty-johtimiset verbit ovat tavallisesti refleksiivisiä, eli niille on ominaista subjektin (agentin) toiminnan kohdistuminen subjektiin itseensä. Osa johdoksista on "täysin omia", eli niillä kaikilla ei ole edes ne-johtimista vastinetta suomen muissa murteissa eikä yleiskielessä (esim. pessenty, voistu). Esitän kaikki verbit preesensin yksikön 3 . persoonassa, jolloin $n t u / n t y$-johtimisten erikoisgeminaatiota (esim. suurenttu) ei tarvitse ottaa huomioon ja ntu/ntyjohtimiset rinnastuvat paremmin stu/styjohtimisten kanssa.

Lounaismurteissa on suuri määrä sellaisia $n t u / n t y$-johtimisia verbejä, joissa johdinta edeltää välittömästi kannan vokaali $e$ ja joita voisi täten nimittää entu/ enty-johdoksiksi. Muita vokaaleita ei tuossa asemassa juuri esiinny, ja näitten poikkeusten lähemmän tarkastelun sivuutan tässä kirjoituksessa. Itse johdin $-n t u / n t y$ on normaalisti astevaihtelun $(-n t-\sim-(n) n-)$ ja erikoisgeminaation (-nt$\sim-n t t-)$ alainen. Johdoksissa on adjektiivi- 
kantaisten lisäksi myös verbikantaisia. Koska useimmat tarkasteltavista johdosverbeistä kuvaavat laajasti ottaen subjektin tilan muutosta, kutsun verbejä yksinkertaisesti translatiiviverbeiksi, vaikka jotkut niistä, kuten rohkentu 'uskaltaa, tohtii', ovat aikojen kuluessa menettäneet varsinaisen translatiivisen luonteensa. Translatiivisuus tulee näin siis määritellyksi väljemmin kuin Isossa suomen kieliopissa (ISK \$ 337). Tutkimani translatiiviverbit tarkoittavat yleensä kuitenkin Hakulisen (1979: 281) translatiiviverbeille antaman määritelmän mukaisesti subjektin muuttumista siksi tai joutumista siihen tilaan kuin mitä kantasana ilmaisee.

Valtaosa tarkasteltavista entu/entytranslatiiviverbeistä jakaantuu kantasanojensa ja rakenneominaisuuksiensa puolesta kahteen pääryhmään, joita nimitän lyhyesti komparatiiviverbeiksi ja geminaatioverbeiksi. Näitten lisäksi lounaismurteissa on joitain yksittäisiä entu/ enty-verbejä, jotka eivät selvästi kuulu kumpaankaan ryhmään, sillä ne sisältävät vieraita piirteitä (ks. alaviitettä 2). Kolmannen ryhmän muodostavat stu/ $s t y$-johtimiset likaantumisverbit, jotka on johdettu substantiivikannoista.

\section{Komparatiiviverbit}

Komparatiiviverbeiksi kutsun niitä johdoksia, joiden lähtömuodoksi voidaan katsoa kaksitavuisen adjektiivin komparatiivimuoto. Koska nyt rajoitutaan ainoastaan entu/enty-segmentin sisältäviin translatiiviverbeihin, on kanta-adjektiivin oltava kaksitavuinen ja $e$ - taikka $a / \ddot{a}$ vartaloinen. Tällaisia ovat siis esimerkiksi seuraavat: suur : suurempi $\rightarrow$ suurentu; kova: kovempi $\rightarrow$ koventu.

Verbien yhteys komparatiiviin tulee erityisen ilmeiseksi juuri $a / \ddot{a}$-vartaloisilla kanta-adjektiiveilla, joita on huomattavasti enemmän kuin $e$-vartaloisia. Adjektiivin toisen tavun $a / \ddot{a}$-vartalovokaalihan on tunnetusti muuttunut komparatii- vissa ja vastaavassa translatiiviverbissä - kuten vastaavassa kausatiiviverbissäkin $-e: k s i$. Näin syntyneet vartalo-e:t ovat siis geneettisesti samat, kuten jo Kettunen (1924: 62) on esittänyt. Hän katsoo komparatiivin e:n ulottaneen analogiavaikutustaan myös verbeihin. Kyseessä on Nymanin (1974: 237-238) mukaan $e$-vartalovariantissa "ikonisesti" toteutuva komparatiivinen funktio (vrt. myös Laakso 1990: 99-100).

Komparatiivilla ja vastaavalla translatiiviverbillä on yhteisenä piirteenä vielä kantavartalon heikkoasteisuus tapauksissa, joissa vartalo sisältää astevaihtelun alaisen konsonantin tai geminaatan. Asia on sinänsä luonnollinen toisen tavun umpinaisuuden vuoksi, eikä tapauksia tunnetakaan juuri enempää kuin seuraavat kuusi tai seitsemän:

$$
\begin{aligned}
& \text { soukka: soukempi } \rightarrow \text { soukentu } \\
& \text { piukka: piukempi } \rightarrow \text { piukentu } \\
& \text { jyrkkä: jyrkempi } \rightarrow \text { jyrkenty } \\
& \text { tarkka: tarkempi } \rightarrow \text { tarkentu } \\
& \text { pitkä : piðempi } \rightarrow \text { piðenty } \\
& \text { halpa: halvempi } \rightarrow \text { halventu } \\
& \text { kiltti }: \text { kiltempi } \rightarrow \text { kiltenty (?) }
\end{aligned}
$$

Näistä esimerkeistä voitaneen päätellä, ettei niiden kehitykseen sovi $n e$-johtiminen välivaihe (esimerkiksi *soukkenepi) niiden vaatiman vahvan asteen vuoksi. Verbit voidaan nähdäkseni siis ymmärtää suoraan komparatiivista syntyneiksi: $e$-vartalovokaali ja heikko aste sitovat kolmikon soukempi-soukenta-soukentu jäsenet luontevasti yhteen, jolloin ei oikeastaan tarvita kausatiivista soukentavälivaihettakaan. ${ }^{2}$

1. Seikkaa vahvistaa vielä lounaismurteissa tunnettu poikkeuksellinen kolmikko paksempipaksenta-paksentu, jolla on vastineensa virossakin: paksem-paksendab-paksendub.

2. Välivaiheena voisi tuskin olla kausatiivista nta/ntä-johdostakaan, koska tällainen on selvästi esiintynyt vain muutamassa tunnetussa tapauksessa hupentu, kykenty, pakentu, tarkentu ('tarke- 
Vastaava ilmeinen yhteys komparatiiviin on myös astevaihteluttomilla rinnakkaistapauksilla, joita on paljon ja jotka ovat muuten samanlaisia kuin edelliset. Esimerkkejä ovat piänenty, vähenty, lyhenty, enenty, pahentu, vanhentu, nuarentu, hiljenty, laiskentu, alentu, ylenty, kylmenty, julmentu 'rumenee', tummentu, nöörenty 'notkistuu', kypsenty, löysenty, syventy, selventy, harventu, vahventu, loiventu, helventy (helva 'halpa'), tyhjenty tyhjänty ja parentu $\sim$ parantu. Eri asia on, että lounaismurteiden ulkopuolella ja yleiskielessä vastineet ovat valtaosaltaan $n e$-johtimisia.

Tähän johdostyyppiin ovat ilmeisesti mukautuneet translatiiviverbit ohentu $(\leftarrow$ ohu $(a))$, lyhenty $(\leftarrow$ lyhy $(\ddot{a}))$ ja keventy $\left(\leftarrow{ }^{\star} \operatorname{kev} y(\ddot{a})\right)$, joiden kanta-adjektiivit esiintyvät murteessa myös muodoissa ohkane(n), lyhkäne(n) ja köykäne(n).

Komparatiiviverbien joukko on Suomen lounaisissa (kuten muissakin murreryhmissä erilaisin johtimin) laaja ja vakiintunut; vakiintuneeksi ja yleensä translatiiviseksi voidaan katsoa myös niiden entu/enty-yhdysjohdin. Koska tämän ryhmän verbien rakenteeseen lisäksi kytkeytyy vartalokonsonantin astevaihtelu, se voi merkitä rakennetyypin olevan iältään vanhempi kuin seuraavaksi käsiteltävä geminaatioverbien rakennetyyppi, jossa puolestaan vallitsee nuorempi ilmiö, lounaismurteiden erikoisgeminaatio.

\section{Geminaatioverbit}

Lounaismurteiden erikoisgeminaatio (ks. Rapola 1966: 30-32) kahdentaa 1. tavunrajalla obstruentin $(k, t, p, s)$, kun sanan toiseen tavuun on supistuman kautta muodostunut pitkä vokaaliaines; tämä vokaaliaines on myöhemmin lyhentynyt. Geminaatio on kehittynyt lounaismurtei-

nee'), tokentu, joiden lähtökohta ei liene adjektiivi; nuo (nykyäänkin tunnetut) lounaissuomalaiset sanat loukkaavat astevaihtelusääntöä eivätkä kaikki ole nykymurteessa translatiivisia. siin myöhemmin kuin astevaihtelu; ajoitusta on pohtinut muiden muassa Rapola (mts. 31-32).

Kielessä runsaasti esiintyneistä * $e \delta a /$ $e \delta a$-loppuisista nomineista, pääasiassa adjektiiveista, on aikanaan syntynyt monia translatiivisia verbejä siten, että nominin loppuun on sulautunut aiemmin komparatiivista kehittynyt johdin ${ }^{*}$-entu/ enty. Ilmeiseltä näyttää suunnilleen seuraavan mallin mukainen suora tie adjektiivista entu/enty-verbiin:

\section{Malli 1: ${ }^{\star} k o r k e \delta a \rightarrow{ }^{*} k o r k e \delta e n t u v i>$} ${ }^{*}$ korkeentuvi $>{ }^{*}$ korkkentuvi $>$ korkkentu

Sulautumisen jälkeen tapahtuu supistuma ja tämän lisäksi geminaatio silloin, kun supistuman seurauksena syntyneen pitkän vokaalin edellä on obstruentti ja muuten geminaatiolle mahdollinen äänneympäristö. Kutakuinkin näin olisivat kehittyneet ryhmän A geminaatioverbit, joita käytetään Maskun murrealueella vieläkin. Geminaatioverbit käsittävät pääasiassa denominaalisia (A) mutta jonkin verran myös deverbaalisia johdosverbejä (B). Molemmissa esiintyy siis ensimmäisellä tavurajalla obstruentissa $(k$, $t, p, s)$ lounaismurteiden erikoisgeminaatio aina sanan konsonanttisysteemin sen salliessa, vaikka ainakin nykyään tässä on hieman horjuntaa. ${ }^{3}$

\section{A. Adjektiivilähtöisiä johdoksia}

$\begin{array}{ll}\text { korkkentu } & \text { 'korottuu, korkenee' } \\ \text { oikkentu } & \text { 'oikenee, suoristuu' } \\ \text { vaikkentu } & \text { 'vaikeutuu' } \\ \text { selkkenty } & \text { 'selkenee' } \\ \text { sakkentu } & \text { 'sakenee' } \\ \text { val(k)kentu 'valkenee' }\end{array}$

3. Ryhmien A ja B "geminaatioverbeihin" olen rinnastanut myös tosiasiassa geminaatiottomia verbejä (esim. rohkentu, pimenty), koska näiden kehityskulut malleissa 1 ja 2 ovat geminaatiota lukuun ottamatta samanlaiset kuin geminoivilla verbeillä. 


\begin{tabular}{|c|c|}
\hline kerkkenty & 'ohenee (neste)'4 \\
\hline soippentu & $\begin{array}{l}\text { 'soipenee, jäähtyy (kuuma } \\
\text { vesi)' }\end{array}$ \\
\hline turppentu & $\begin{array}{l}\text { 'turpoaa, turpenee (puu- } \\
\text { astia, puuvene)' }\end{array}$ \\
\hline helppenty & $\begin{array}{l}\text { 'helpottuu, kevenee' } \\
\text { (helppiä 'kevyt, helppo') }\end{array}$ \\
\hline leppenty & 'leppyy, lauhtuu' \\
\hline lenssenty & $\begin{array}{l}\text { 'lauhtuu, lämpiää (sää)' } \\
\text { (lenssiä 'lauha') }\end{array}$ \\
\hline rohkentu & $\begin{array}{l}\text { 'rohkenee' (ei translatiivi- } \\
\text { nen) }\end{array}$ \\
\hline pimenty & 'pimenee' \\
\hline tyrmenty & $\begin{array}{l}\text { 'kovenee, ankaroituu' } \\
\text { (tyrmiä 'vahva; kova, } \\
\text { ankara, vaativa') }\end{array}$ \\
\hline sitkent & 'sitkenee, sitkistyy' \\
\hline vailen & $\begin{array}{l}\text { 'vajenee' (johtosuhde epä- } \\
\text { selvä) }\end{array}$ \\
\hline
\end{tabular}

\section{B. Verbilähtöisiä johdoksia}

$\begin{array}{ll}\text { kulkkentu } & \text { 'kulkeutuu' } \\ \text { sulkkentu } & \text { 'sulkeutuu' } \\ \text { tekkenty } & \text { 'parantuu, tointuu' } \\ \text { aukkentu } & \text { 'aukeaa' } \\ \text { pessenty } & \text { 'tulee pestyksi' } \\ \text { laskentu } & \text { 'laskeutuu, alenee' } \\ \text { kualentu } & \text { 'kuoleentuu; puutuu' } \\ \text { tuulentu } & \text { 'tuulettuu' } \\ \text { tulentu } & \text { 'tuleentuu's }\end{array}$

Näillä kaikilla translatiivisuus ei ole aivan selkeää, mutta kaikissa tapauksissa voinee puhua ainakin subjektin tilanmuutoksesta. Refleksiivisyyskin vallitsee.

Komparatiiviverbit ja geminaatioverbit ovat samanjohtimisina ulkoisesti toisiaan muistuttavia, mutta ne ovat syntyneet eri motivaatiosta ja eri prosessein, kuten edellä olen esittänyt. Niitä voi etsiä samanlaisilla hakuehdoilla, mutta A-

4. Tämä verbi tavataan Uudessakaupungissa ja Kalannissa, ja siellä tunnetaan myös kantaadjektiivi kerkki(ä) 'juokseva, notkea (neste)' (ks. Winter 1978: 48).

5. SKES:n mukaan tuleentua-verbi johtuu tulla-verbistä. ja B-ryhmien geminaatiollisia verbinmuotoja on ollut vaikea löytää aiemmasta tutkimuskirjallisuudesta tai Suomen murteiden sanakirjasta; viimeksi mainitusta olen löytänyt vain Karjala Tl:ssä tavatun partisiippimuodon korkkentunu hakusanan korkeentua kohdalta. Itselleni kyseiset verbimuodot ovat aivan luontevia, ja käytän niitä myös puheessani. Muistan äitinikin (s. 1909) niitä käyttäneen: hän puhui esimerkiksi paatin turppentumisest. Nykyään kuulee usein A- ja Bverbien geminaatiottomia variantteja, sellaisia kuin korkentu ja kulkentu. Ne vaikuttavat uudennoksilta; geminaatio on selvästikin katoava ominaisuus.

Huomiota kiinnittää se, että ainakin puolella A-ryhmässä luetelluista verbeistä on lounaismurteiden ulkopuolella (tai ainakin kirjakielessä) ne-johtiminen samankantainen ja samanmerkityksinen vastine: korkenee, oikenee, selkenee, sakenee, valkenee, rohkenee, soipenee, turpenee, pimenee. Vaikka lounaismurteissa katsottaisiinkin koko A-ryhmän lähtökohdaksi juuri tämmöiset vastineet, sama ei tunnu todennäköiseltä B-ryhmän suhteen (ks. alaviitettä 2). Ehdotan, että sekä A- että B-ryhmien johtamisen lähtökohdaksi otettaisiin $e$-vartalovokaalin sisältävä kantasana: A-ryhmässä ${ }^{*} e \delta a / e \delta a$ johtiminen ${ }^{6}$ adjektiivi ja B-ryhmässä aina verbi, jolla on $e$ :hen päättyvä vartalo, esimerkiksi *kulke-. Tällainen "sukulaisuus" voinee analogian tietä kehittää molemmista ryhmistä lopulta hyvin samanhahmoisia entu/enty-johdosverbejä geminaatioineen - sellaisia kun kiistatta on. Mahdollinen on myös supistumaverbeihin perustuva analogia, mikä tuottaisi pitkän vartalovokaalin B-ryhmän verbeihin. B-ryhmän kehityksessä voisi uumoilla myös mallia 1 enemmän tai vähemmän muistuttavaa kehityskulkua:

6. Itämerensuomessa nykyisin johtimeen kuuluva e on Korhosen (1981: 322) mukaan lohjennut varsinaisista $e$-vartaloista. 
Malli 2: ${ }^{*}$ kulkeva $\rightarrow{ }^{*} k u l k e v e n t u v i>$ ${ }^{*}$ kulkeentuvi $>{ }^{*}$ kulkkentuvi $>$ kulkkentu

Tässäkin mallissa on supistuma ja sen aiheuttama geminaatio; huomattakoon, että lähtömuodoksi sopisi luontevasti 1. partisiippi, ei 1. infinitiivi.

Vedoten Agricolan kieleen Räisänen (1985: 10) pitää itsestään selvänä, että lounaismurteissa olisivat alkuperäisempiä nejohtimiset translatiiviverbit, joista valtaosa on sitten muuntunut vastaaviksi $n t u-$ johtimisiksi verbeiksi. Siirtymäprosessissa hän sanoo (mas. 27) olleen välivaiheena tyyppiä *pimentä- olevan kausatiivisen verbin, jossa olisi ollut translatiivisen osan -ne ja kausatiivisen osan -ta/tä sulaumana yhdysjohdin -nta/ntä. Tästä olisi luonnollista päästä lounaismurteiseen refleksiiviseen translatiiviverbiin, kuten pimenty. Geminaatiotapauksia, niin kuin turppentu, on tällöin tosin vaikea selittää. Samaten jäävät jälleen B-ryhmän verbit selityksettä. Ainoat tuntemani tapaukset, jotka viittaavat mainitunlaiseen kausatiivivälivaiheeseen, ovat alaviitteessä 2 mainitut viisi verbiä (esim. hupentu).

B-ryhmän viidessä ensimmäisessä esimerkissä nähdään $k: n$ ja $s: n$ geminaatio, mutta loput viisi ovat rinnakkaistapauksia, joissa ei geminaatio tietenkään voi toteutua.

Mitä tulee A- ja B-ryhmiin kuuluvien verbien yhteiseen tyyppinimeen geminaatioverbit, tämä ei ole geminaatiottomien kohdalla oikein kuvaava. Käytän sitä nyt vain paremman puutteessa. Onhan geminaatiottomien kehityskulku lähtökohtineen hyvin samanlainen kuin geminaatiollisten: laskeva $\rightarrow \ldots>$ laskentu; kulke $\delta a \rightarrow$... > kulkkentu; molemmissa tapahtuu supistuma, mutta ensin mainitusta puuttuu vain geminaatio; sen korvaa tavallaan analogia geminaatiollisten taholta. B-ryhmän verbit johtuvat selvästikin tietyistä toisista verbeistä samaan tapaan kuin A-ryhmän verbit on johdettu tietyistä adjektiiveista. Esimer- kiksi kulkkentu-verbin kantasana on verbi ${ }^{\star} k u l k e-$. Nämä kantasanana toimineet verbit on yleensä helppo tunnistaa, ja ne eivät yleensä ole refleksiivisiä, mutta kaikki B-johdokset ovat samoin kuin A-ryhmän johdoksetkin. Johdosten geminaatiotaipumukseen voi vaikutusta olla silläkin, että geminaatiota esiintyy myös joillain kantasanana olevilla ei-supistumaverbeillä (esim. 1. inf. kulkke, sulkke); joskus kuulee lisäksi sellaisia 1. infinitiivin muotoja kuin tekke tekki, näkke näkki (mm. Mynämäessä ja Honkilahdessa).

Tapausten A ja B mallien 1 ja 2 mukaiset diakroniat lounaismurteissa tuottaisivat refleksiivisiä johdoksia, mistä on näkyvänä merkkinä lopputuloksissa oleva refleksiivinen päätetavu -tu/ty. Kehityskulkuihin ei nähdäkseni sopisi toista refleksiivisyyden ilmaisinta ${ }^{*} u / y$ johtimen *-untu/ynty-alkusegmenttinä, jollaiseen Hakulinen (1979: 279) viittaa. Luontevammin sopii -entu/enty- geminaatioverbien tapauksessa mallien 1 ja 2 perusteella, ja aivan itsestään selvästi tämä johdin sopii komparatiiviverbeille, joissa $e$-segmentti periytyy komparatiivista. (Vrt. myös Rapola 1966: 169-170.)

Geminaation mahdollistavia translatiiviverbejä on lisäksi jonkin verran muitakin kuin entu/enty-loppuisia, esimerkiksi sekkantu 'sekoittuu; sotkeutuu; sekoaa (päästään)', färskinty 'härskiintyy, eltaantuu' (färski 'eltaantunut'), kokkontu 'kerääntyy, kertyy', koruntu 'käristyy, korventuu', härssynty 'ärsyyntyy' (härsyttä 'ärsyttää), lissänty'lisääntyy' ja rystönty 'rustottuu' (rystö 'rusto'). Ohitan ne tässä vain maininnalla. Verbissä erkantu ei odotuksenvastaisesti ilmenekään geminaatiota; verbi vaikuttaisi olevan Lounais-Suomeen muualta tullut uudehko laina.

\section{Likaantumisverbit}

Edellä käsitellyt komparatiiviverbit ovat adjektiivikantaisia; geminaatioverbeissä on puolestaan sekä adjektiivi- että verbi- 
kantaisia. Lounaismurteissa käytetään myös määrätyyppisiä substantiivilähtöisiä translatiiviverbejä, jotka nekin ovat refleksiivisiä. Tavallisin on Maskun murrealueelle tunnusomainen stu/styverbinjohdin, joka korvaa monesti yleiskielen ja muiden murteiden ntu/ntyjohtimen. Esimerkiksi ${ }^{*}$ likkantu tai ${ }^{*} l$ kantu ('likaantuu') on lounaismurteiden alueella laajalti tuntematon, ja sen asemesta sanotaan likastu. Muita samoin johdettuja verbejä on alueella epälukuinen määrä, ja ne olen nimennyt likaantumisverbeiksi $i^{7}$ Nämä stu/sty-johtimella yleensä kaksitavuisesta substantiivista muodostuneet verbit kuvaavat kantansa ilmaisemalla aineella tahriintumista; astevaihtelullisesta kantavartalosta otetaan aina vahva-asteinen variantti - huolimatta umpitavusta - joten johdostyyppi lienee nuori. Johdin tunnetaan, jos kohta harvinaisempana, Maskun murrealueen ulkopuolellakin, kuten Sauvossa ja Kalannissa (hikisty), Mynämäessä (kurastu) ja jopa lounaisten välimurteitten puolella, kuten Pöytyällä (kualastu); nämä esimerkit löytyvät Suomen murteiden sanakirjasta (s.v. hikistyä, kurastua, kuolastua). Koiviston (1995: 138) refleksiiviverbejä käsittelevän väitöskirjan taulukossa 10 näytetään lounaismurteiden pohjoishaaran osalta refleksiivisistä verbijohdoksista vain tyyppi $(V) V n t U$, joka kattaa käsillä olevan artikkelin komparatiivi- ja geminaatioverbit. Likaantumisverbejä ei tietääkseni ole käsitelty muussakaan aiemmassa tutkimuskirjallisuudessa.

Muita likaantumisverbejä ovat nokistu, multastu, soopastu, paskastu, tomustu, kurastu, savistu, nuljustu, jaohostu, santastu, rasvastu, sau(hu)stu, kualastu, karvastu, tuhkastu, porostu, roskastu, röhnästy, soosistu, piimästy, hikisty ja räkästy. Kanta voi olla rajatapauksissa yksi- tai kolmitavuinenkin (voistu, mähtäräisty -

7. Murteen kantaa kuvaavampi nimitys olisi likastumisverbit. substantiivi mähtärä tarkoittaa jotakin 'tahmeaa likaa'; verbin äi-diftongi säilyy sivupainon ansiosta). Olen kuullut niinkin oudon sanan kuin piarustu (liikaa sisällä oleskeleva ihminen "pierustuu"). Johdokset ovat enemmän tai vähemmän tilapäiskäyttöisiä, mutta niitä voi tarvitessa luoda sangen vapaasti - päin vastoin kuin yleiskielessä, jossa herkemmin turvaudutaan sellaisiin analyyttisiin rakenteisiin kuin esimerkiksi tulee räkäiseksi. Yllä lueteltujen likaantumisverbien kantasanoista johtuu suomen yleiskielessä vain joitakin $u t u$ / $y t y$ - sekä $V V+n t u / n t y$-johdoksia, semmoisia kuin nokeutuu ja nokeentuu. Verbi likastu on edellä mainituista translatiiviverbeistä kaikkein yleisin, ja sen voi sanoa olevan produktiivinen ja tavallaan generoivan kaikki muut, kun vain sen kantavartalo korvataan muita likaavia aineita tarkoittavilla sanoilla vahva-asteisina. On kuitenkin luonnollisempaa sanoa kunkin likaantumisverbin substantiivikannan itsenäisesti käyttävän johdinta -stu/sty. Johdin käsittää kausatiivisen komponentin - $t$ - ja refleksiivis-passiivis-automatiivisen komponentin $-u / y$ - (vrt. Räisänen 1988: 20-23).

Miten sitten likastu ja muut vastaavat likaantumisverbit ovat syntyneet? Substantiivilla lika on suomessa adjektiivijohdos lika(i)ne(n), jonka ensimmäinen $n$ korvautuu obliikvimuodoissa s:llä. Syntyy siis obliikvivartalo lika(i)se-, josta voi tehdä edelleenjohdoksia ja saada kausatiiviverbin lika(i)sta. Kun tästä vielä kuluu $i$ vokaali pois, on kausatiivi yksinkertaistunut lounaismurteiseen muotoonsa, josta johtuu edelleen vastaava translatiiviverbi likastu. Näin on lika-substantiiville kehittynyt vaiheittain kaksi uutta verbiä:

$$
\begin{aligned}
& l i k a \rightarrow \text { lika }(i) n e(n) \rightarrow \text { lika(i)se- } \rightarrow \\
& \text { lika(i)sta }>\text { likasta } \rightarrow \text { likastu }
\end{aligned}
$$

Lienee mahdotonta keksiä muunlaista selitystä translatiiviselle verbinjohtimelle $-s t u / s t y$. 
Kutakin likaantumisverbiä vastaa murteessa aina samankantainen kausatiiviverbi, siis likasta, nokista, multasta ja niin edelleen; kausatiivi onkin ilmeisenä välivaiheena, jonka kautta refleksiivinen likaantumisverbi on muodostunut. Kehityksellä lienee yhteisiä juuria viron kanssa, sillä viron kirjakielestäkin löytyy suomen lounaismurteisten verbien kanssa samanjohtimisia translatiivisten ja kausatiivisten verbien pareja, esimerkiksi ligastub, ligastab; nõgistub, nõgistab; limastub, limastab; liivastub, liivastab - lounaissuomalaisten translatiivijohdosten ilmeisiä vastineita. Kulonen-Korhonenkin (1985: 294) mainitsee tämänkaltaisia verbipareja $-t A \sim-t U$.

Sitä vastoin suomalaisissa sanakirjoissa ei juuri ole nyt tarkasteltavia likaantumisverbejä muita kuin Nykysuomen sanakirjassa mainittu kurastua. ${ }^{8}$ Vaikka Hakulisen (1979) suomen kielen rakennetta ja kehitystä koskeva teos on hyvin kattava, siinä eivät nominikantaisen verbinjohtimen -(i)stu/sty (mts. 297) yhteydessä tule mitenkään esille likaantumisverbit. Johtimen -(i)sta/stä (mts. 295) kohdalla mainitaan kausatiivinen esimerkki savustaa ja Nykysuomen sanakirjassa tämän sanan yhteydessä myös passiiviverbi savustua, mutta savustaa-sanan merkityksinä mainitaan vain 'kypsentää savussa', 'puhdistaa savulla' ja 'karkottaa savulla', eli puuttuu merkitys 'tahria savulla'.

Edellä esittämäni muotoketju lähtee siis substantiivin adjektiivijohdoksesta. Räisänen (1988: 50) toteaa Nykysuomen sanakirjan useimmilla inen-johtimisista adjektiiveista ynnä muista johdetuilla translatiivisilla $(s) t u$-johdosverbeillä olevan kausatiivivastine (samaistaa jne.). Hän mainitsee suomen $s t u$-johdosten olevan heikkoasteisia (esim. pelästyä), mutta tu-johdosten säilyttävän kantavartalon

8. Selvennykseksi sanottakoon, etten nyt siis tarkoita sellaisia verbejä kuten kellastua, mehustua, soistua ym., vaan ainoastaan sellaisia, jotka merkitsevät kantansa aineella tahriintumista. vahva-asteisena (esim. aikaistua); viimeksi mainittu tieto näkyisi olevan sopusoinnussa lounaismurteiden likaantumisiverbien vahva-asteisuuden kanssa.

Voidaan todeta, että likaantumisverbit muodostavat lounaismurteille ominaisen, morfologisesti ja semanttisesti hyvin yhtenäisen ryhmän. Ryhmän kokoa on kuitenkin vaikea arvioida, sillä näitä johdoksia voidaan muodostaa melko vapaasti erilaisia likaavia aineita tarkoittavista substantiiveista.

\section{Yhteenvetoa}

Suomen lounaismurteissa ovat translatiivisten verbien joukossa hallitsevassa asemassa ne johdokset, joiden johtimena on -ntu/nty. Usemmissa tapauksissa tämä suffiksi liittyy kantavartalon vokaalin $e$ perään, jolloin voidaan puhua entu/entyloppuisista translatiiviverbeistä. Nämä jakaantuvat oletetun syntytapansa mukaan niin sanottuihin komparatiiviverbeihin (esim. halventu) ja geminaatioverbeihin (esim. selkkenty). Jälkimmäinen verbityyppi vaikuttaa nuoremmalta, koska sen kehitykseen on liittynyt lounaismurteiden erikoisgeminaatio; tämä ilmiö näyttäisi myös sulkevan verbien kehityshistoriasta pois ne-välivaiheen ( ${ }^{\star}$ selkenepi). Lounaismurteille tyypillisiä ovat niin ikään stu/sty-johtimiset, monenlaista 'likaantumista' tarkoittavat translatiiviverbit, joita olen nimittänyt tässä likaantumisverbeiksi, sekä vastaavat kausatiivit (esim. tuhkastu ja tuhkasta). Kumpiakaan ei yleiskieli tunne, eivätkä tunne kaikki suomalaisetkaan, minkä voi päätellä seuraavasta Vauva.fi-keskustelufoorumin kommentista: "Likastaa? Verbi on liata. Opettele suomen kieltä."

JUSSI PAHIKKALA pahio@wakkanet.fi

Kirjoittaja on matemaatikko ja kielitieteen harrastaja. 


\section{Lähteet}

HAKUlinen, LAURI 1979: Suomen kielen rakenne ja kehitys. Neljäs painos. Helsinki: Otava.

ISK = HAKUlinen, AUli - Vilkuna, Maria - Korhonen, Riitta Koivisto, Vesa - Heinonen, Tarja Ristta - Alho, Irja 2004: Iso suomen kielioppi. Helsinki: Suomalaisen Kirjallisuuden Seura.

Kettunen, Lauri 1924: Miten on selitettävä suomenkielen $a \sim e, \ddot{a} \sim e$ vaihtelu? - Virittäjä 28 s. 57-70.

KoIvisto, VESA 1995: Itämerensuomen refleksiivit. Suomalaisen Kirjallisuuden Seuran Toimituksia 622. Helsinki: Suomalaisen Kirjallisuuden Seura.

Korhonen, Mikкo 1981: Johdatus lapin kielen historiaan. Helsinki: Suomalaisen Kirjallisuuden Seura.

Kulonen-Korhonen, Ulla-Maija 1985: Deverbaalisten $U$-johdosten semantiikkaa. Suomi 161. Helsinki: Suomalaisen Kirjallisuuden Seura.

LAAKsO, JOHANNA 1990: Translatiivinen verbinjohdin NE itämerensuomalaisissa kielissä. Suomalais-Ugrilaisen Seuran
Toimituksia 204. Helsinki: Suomalais-

Ugrilainen Seura.

Nykysuomen sanakirja. Helsinki: WSOY 1980.

Nyman, Mart Ti 1974: Synkronisen rekonstruoinnin rajat. - Virittäjä 78 s. 223-242.

Rapola, Mart ti 1966: Suomen kielen äännehistorian luennot. Helsinki: Suomalaisen Kirjallisuuden Seura.

RÄIsänen, Alpo 1985: Suomen kielen ne- ja $n t u$-, $n t y$-johtimiset translatiiviverbit. Virittäjä 89 s. 1-32.

— 1988: Suomen kielen $U$-johtimiset verbit. Suomi 141. Helsinki: Suomalaisen Kirjallisuuden Seura.

SKES = Suomen kielen etymologinen sanakirja. Helsinki: Suomalais-Ugrilainen Seura. 1978.

Suomen murteiden sanakirja. Kotimaisten kielten keskuksen verkkojulkaisuja 30. Helsinki: Kotimaisten kielten keskus. URN:NBN:fi:kotus-20111o. http://kaino. kotus.fi/sms (5.4.2019).

Vauva.fi-keskustelufoorumi. https://www. vauva.fi/comment/31653725 (17.11.2017).

Winter, Helmer 1978: Meijän kiäl. Sukkeli sanoi ja sanamparssi Uurestkaupunkist ja muuhalt Vakka-Suamest. Uusikaupunki: Turu Uurenkaupunkin Kilt.

\section{Ajalla on paikkansa}

Maija Surakka: Ajan paikka. Ajanilmausten kehityspolkuja lasten kielessä. Dissertations in Education, Humanities, and Theology 139. Joensuu: Itä-Suomen yliopisto 2019. 256 s. ISBN 978-952-61-2973-0. Saatavilla verkossa osoitteessa http://epublications.uef.fi/pub/ urn_isbn_978-952-61-2973-0/.
Lapsen kieli on sellainen ihme, että sen ääreen ovat monet tutkijat pysähtyneet, tosin eri syistä ja lähtökohdista. Perinteisesti se on kiinnostanut psykologiaa ja kasvatusalaa, mutta yhä enemmän myös kielentutkijat ovat etsineet siitä teoreettisia tarttumapintoja. Kansainvälisistä lapsenkielen tutkijoista nykyisin ehkä laa- 